Pacific Journal of Mathematics

PERIODIC SOLUTIONS OF HIGHER ORDER SYSTEMS 


\title{
PERIODIC SOLUTIONS OF HIGHER ORDER SYSTEMS
}

P. W. BATES AND J. R. WARD, JR.

\begin{abstract}
Results are given providing sufficient conditions for the existence of periodic solutions higher order nonlinear vector differential equations. The conditions include the possibility of both sublinear and superlinear growth in the nonlinear terms.
\end{abstract}

1. Introduction. Consider the system of equations

$$
u^{(n)}+g\left(t, u, u^{\prime}, \cdots, u^{(n-1)}\right)=f(t), \quad 0<t<T,
$$

where $u, g$, and $f$ are $k$-vectors. We will establish the existence of $T$-periodic solutions to (1.1) for large classes of nonlinearities $g$ and forcing terms $f$. In particular we include cases where $g$ is bounded, sublinear, or superlinear in $u$, with arbitrary growth in the other arguments of $g$ in the latter case. We also include cases in which $g$ is mildly singular in $t$ or vanishes at an endpoint of the interval.

The second order scalar version of (1.1) has received attention recently with new and interesting results (see, e.g., [2] and [3]). The second order vector case of (1.1) has also been investigated by several authors recently with interesting results, often based on the sign of $x \cdot g$ (see, e.g., [1], [5], [6]). Recently the second author in [8] obtained results which apply to higher order vector equations which lead to operators nonnegative outside a large ball.

Our results here do not depend on sign conditions in the sense that if the function $g$ in (1.1) satisfies our conditions so does $-g$. Also our results do not depend on the existence of a Nagumo function for $g$. Roughly speaking we assume that the nonlinearity $g$ is either sublinear at infinity (see Cor. 2.2) or superlinear at the origin (see Cor. 2.3). Although we see our results as being of principle interest for higher order scalar and vector equations we obtain results which appear to be new even in the second order scalar case (see Example 3.3). We wish also to remark that while our results are all stated for periodic boundary conditions, our methods could be applied equally well to some other boundary value problems, e.g., the Neumann problem $x^{\prime}(0)=x^{\prime}(T)=0$ for second order equations.

For the proof of our result we will rely on an abstract result of Mawhin [4] which is an extension of the Leray-Schauder continuation theorem.

Let $X$ and $Z$ be normed vector spaces, $L: D(L) \subseteq X \rightarrow Z$ a linear 
Fredholm mapping of index zero and $N: X \rightarrow Z$ a continuous mapping. It follows that there exist continuous projections $P: X \rightarrow X$ and $Q: Z \rightarrow Z$ such that $\operatorname{Im}(P)=\operatorname{Ker}(L)$ and $\operatorname{Im}(L)=\operatorname{Ker}(Q)=\operatorname{Im}(I-Q)$. Moreover the mapping

$$
L: D(L) \cap \operatorname{Ker}(P) \subseteq(I-P) X \rightarrow \operatorname{Im} L
$$

is invertible; denote its inverse by $L^{-1}$. Let $G$ be an open bounded subset of $X$. The mapping $N$ is said to be $L$-compact on $\bar{G}$ if $Q N(\bar{G})$ is bounded and $L^{-1}(I-Q) N: \bar{G} \rightarrow X$ is compact. Let $J$ be an isomorphism from $\operatorname{Im}(Q)$ onto $\operatorname{Ker}(L)$; such a $J$ exists since these subspaces have the same finite dimension.

Theorem (Mawhin; see [4], p. 40). Let L be a Fredholm mapping of index zero and let $N$ be L-compact on $\bar{G}$. Suppose

(i ) For each $\lambda \in(0,1)$, every solution $u$ of

$$
L u=\lambda N u
$$

is such that $u \notin \partial G$.

(ii) $Q N u \neq 0$ for each $u \in \operatorname{Ker}(L) \cap \partial G$ and $d(J Q N, G \cap \operatorname{Ker} L, 0) \neq 0$. Then the equation $L u=N u$ has at least one solution in $D(L) \cap \bar{G}$. Here $d(\cdot, \cdot, \cdot)$ refers to the Brouwer degree.

We will use the notation:

$$
|a|=\max _{1 \leqq i \leqq k}\left|a_{i}\right| \text { for } \quad a \in R^{k}, \quad L_{1}\left(J, R^{k}\right)
$$

for the integrable functions defined on an interval $J$ and taking values in $R^{k}$, with norm denoted by $\|\cdot\|_{1}$, and $C\left(J, R^{k}\right)$ for the continuous functions, with norm defined by $\|h\|=\sup \{|h(t)|: t \in J\}$.

2. The results. Consider the $n$th order nonlinear system.

$$
u^{(n)}+g\left(t, u, u^{\prime}, \cdots, u^{(n-1)}\right)=f(t), \quad t \in J=(0, T),
$$

where $g: J \times R^{k \times n} \rightarrow R^{k}$ is continuous and $f \in L_{1}\left(J, R^{k}\right)$. We will impose general conditions on $g$ and $f$ which will allow us to use the Mawhin theorem stated in $\S 1$, and then give special classes of such functions in our corollaries. Section 3 contains some examples.

Let $r=\left(r_{i p}\right) \in R^{k \times n}$ be fixed and define

$$
\Omega=\left\{a \in R^{k \times n}:\left|a_{i p}\right|<r_{i p}, 1 \leqq i \leqq k, 0 \leqq p \leqq n-1\right\} .
$$

Suppose that the function $g$ satisfies

(G1) there exists a function $C: R \rightarrow R^{k}$ such that for $L \geqq 0$ and $j=1, \cdots, k,\left|g_{j}\left(t, u^{0}, \cdots, u^{(n-1)}\right)\right| \leqq L$ for $t \in J$ and $u=\left(u_{i}^{p}\right) \in \bar{\Omega}$ implies that $\left|u_{j}^{0}\right| \leqq C_{j}(L)$, and 
(G2) there exists a function $\beta \in L_{1}\left(J, R^{k}\right)$ such that if $u \in \bar{\Omega}$, then $\left|g_{j}\left(t, u^{0}, \cdots, u^{(n-1)}\right)\right| \leqq \beta_{j}(t), 1 \leqq j \leqq k$.

In the above expressions we are using $u_{i}^{p}$ to represent the element in the $i$ th row and $p$ th column of a real $k \times n$ matrix.

Define the projection $Q$ on $L_{1}\left(J, R^{m}\right), m \geqq 1$, by

$$
Q h=\frac{1}{T} \int_{0}^{T} h(s) d s .
$$

THEOREM 2.1. Suppose that (G1) and (G2) are satisfied and that for $1 \leqq i \leqq k$,

$$
\left\{\begin{aligned}
C_{i}\left(\left|Q f_{i}\right|\right)+T^{n-1}\left(\left\|f_{i}\right\|_{1}+\left\|\beta_{i}\right\|_{1}\right)<r_{i 0}, \\
T^{n-p-1}\left(\left\|f_{i}\right\|_{1}+\left\|\beta_{i}\right\|_{1}\right)^{\prime}<r_{i p}, \quad i \leqq p \leqq n-1 .
\end{aligned}\right.
$$

Further, suppose that

$$
\sum_{i=1}^{k} a_{i} \operatorname{sgn}\left(u_{i}^{0}\right) Q\left[g_{i}\left(\cdot, u^{0}, 0, \cdots, 0\right)-f_{i}\right]>0
$$

for $\left(u^{0}, 0, \cdots, 0\right) \in \partial \Omega$, where $a_{i} \in\{-1,1\}, 1 \leqq i \leqq k$. Then (2.1) has a T-periodic solution.

Proof. We show that the hypotheses of Mawhin's theorem hold with the operators defined below.

Let $X=C^{(n-1)}\left(\bar{J}, R^{k}\right), Z=L_{1}\left(J, R^{k}\right)$, and

$$
G=\left\{u \in X:\left(u(t), \cdots, u^{(n-1)}(t)\right) \in \Omega, t \in \bar{J}\right\} .
$$

Define $L: \operatorname{dom} L \subseteq X \rightarrow Z$ by

$$
\begin{gathered}
\operatorname{dom} L=\left\{u \in X: u^{(n-1)} \in A C(J), u^{(p)}(0)=u^{(p)}(T), 0 \leqq p \leqq n-1\right\}, \\
L u=u^{(n)} \text { for } u \in \operatorname{dom} L .
\end{gathered}
$$

Define $N: X \rightarrow Z$ by

$$
N u(t)=f(t)-g\left(t, u(t), \cdots, u^{(n-1)}(t)\right) \text { for } u \in X .
$$

It is easily verified that $\operatorname{Im} L$ is closed and that $\operatorname{Ker} L=R^{k} \cong Z / \operatorname{Im} L$ and, therefore, $L$ is a Fredholm map of index zero. Define the projections $P: X \rightarrow \operatorname{Ker} L$ and $Q: Z \rightarrow Z$, such that $\operatorname{Im} L=\operatorname{Ker} Q$, by

$$
Q h=\frac{1}{T} \int_{0}^{T} h(s) d s=P h .
$$

The restriction of $L$ to $(I-P) X \cap \operatorname{dom} L$ is one-to-one and so $L$ has a partial inverse,

$L^{-1}: \operatorname{Im} L \rightarrow(I-P) X \cap \operatorname{dom} L . \quad$ Furthermore, since $g$ is continuous and $\operatorname{dom} L$ is compactly imbedded in $X$, it follows that 
$L^{-1}(I-Q) N: X \rightarrow X$ is completely continuous.

We claim that if $u \in \operatorname{dom} L \cap \partial G$ and $0<\lambda<1$, then $L u \neq \lambda N u$.

Suppose this is not the case, then there exists $\lambda \in(0,1)$ and a function $u \in \operatorname{dom} L$ with

$$
u^{(m)}+\lambda g\left(t, u, \cdots, u^{(n-1)}=\lambda f, \quad t \in J .\right.
$$

Furthermore, since $u \in \partial G,\left\|u_{i}^{(p)}\right\| \leqq r_{i p}, 1 \leqq i \leqq k, 0 \leqq p \leqq n-1$, and for some $m$ and $j$ there is a $t^{*} \in \bar{J}$ such that $\left|u_{j}^{(m)}\left(t^{*}\right)\right|=r_{j m}$. Also, by the periodicity condition, there are points $t_{p} \in J$ such that $u_{j}^{(p)}\left(t_{p}\right)=0,1 \leqq p \leqq n-1$.

Integrating the $j$ th row of (2.4) and using the mean value theorem for integrals, gives another point, $t_{0} \in J$, such that

$$
\left|g_{j}\left(t_{0}, u\left(t_{0}\right), \cdots, u^{(n-1)}\left(t_{0}\right)\right)\right|=\left|Q f_{j}\right|,
$$

which implies that $\left|u_{j}\left(t_{0}\right)\right| \leqq C_{j}\left(\left|Q f_{j}\right|\right)$, by (G1). Integrating the $j$ th row of (2.4) $n-m$ times between the indicated limits yields

$$
\begin{array}{r}
u_{j}^{(m)}\left(t^{*}\right)-u_{j}^{(m)}\left(t_{m}\right)=\lambda \int_{t_{m}}^{t^{*}} \int_{t_{m+1}}^{s_{m-1}} \cdots \int_{t_{n-1}}^{s_{n-1}}\left[f_{j}\left(s_{n}\right)-g_{j}\left(s_{n}, u\left(s_{n}\right), \cdots,\right.\right. \\
\left.\left.u^{(n-1)}\left(s_{n}\right)\right)\right] d s_{n} \cdots d s_{m+1} .
\end{array}
$$

Using (G2), it follows that

$$
r_{j m} \leqq T^{n-m-1}\left(\left\|f_{j}\right\|_{1}+\left\|\beta_{j}\right\|_{1}\right), \quad \text { if } \quad 1 \leqq m \leqq n-1
$$

and

$$
r_{j 0} \leqq C_{j}\left(\left|Q f_{j}\right|\right)+T^{n-1}\left(\left\|f_{j}\right\|_{1}+\left\|\beta_{j}\right\|_{1}\right), \quad \text { if } \quad m=0 .
$$

Either case contradicts the hypotheses of the theorem.

Next, because $\operatorname{Ker} L=R^{k}$, the condition that $Q N u \neq 0$ for $u \in \operatorname{Ker} L \cap \partial G$ becomes

$$
Q\left[f-g\left(\cdot, u^{0}, 0, \cdots, 0\right)\right] \neq 0 \quad \text { for } \quad\left(u^{0}, 0, \cdots, 0\right) \in \partial \Omega .
$$

This is guaranteed by (2.3).

Finally, (2.3) implies that $Q N$ is homotopic on $\operatorname{Ker} L \cap \partial G$ to the matrix $A=\operatorname{diag}\left(-a_{i}\right)$, implying that the Brouwer degree, $d(Q N, G \cap \operatorname{Ker} L, 0)$, is nonzero.

The hypotheses of Mawhin's theorem are satisfied and, hence, there exists a function $u \in \operatorname{dom} L \cap \bar{G}$ such that $L u=N u$, that is, $u$ is a $T$-periodic solution to (2.1) and satisfies $\left\|u_{i}^{(p)}\right\| \leqq r_{i p}, 1 \leqq i \leqq k$, $0 \leqq p \leqq n-1$.

REMARKs. (a) The solution, $u$, lies in $C^{n-1}(\bar{J})$ with $u^{(n)}$ only existing almost everywhere. If we assume that $f$ is continuous, then we can conclude that $u^{(n)}$ is continuous on $J$. 
(b) To extend the solution periodically one must, of course, assume that both $f$ and $g$ are $T$-periodic in $t$.

(c) The function $C$ in (G1) is not assumed to be continuous. If $g(t, u)=t u$ on $(0,1) \times R$, for example, and if $|g(t, u)| \leqq L$ for $t \in(0,1),|u| \leqq r$, then we may take

$$
C(L)=\left\{\begin{array}{lll}
0 & \text { if } \quad L=0 \\
r & \text { if } \quad L>0 .
\end{array} \quad \text { (See Corollary } 2.3 \text { and Example } 3.3\right) .
$$

(d) The purpose of (2.3) is to ensure that the Brouwer degree, $d(Q N, G \cap \operatorname{Ker} L, 0)$, is defined and nonzero. A weaker version of (2.3) that is sometimes used is

$$
x \cdot[g(t, x, 0, \cdots, 0)-f(t)]>0 \quad \text { for } \quad t \in J,(x, 0, \cdots, 0) \in \partial \Omega
$$

or

$$
x \cdot[g(t, x, 0, \cdots, 0)-f(t)]<0 \quad \text { on the same set } .
$$

Our first corollary deals with the case where $g$ is sublinear in a certain sense. First some notation:

For all $r \in R^{k \times n}, r_{i p} \geqq 0,1 \leqq i \leqq k, 0 \leqq p \leqq n-1$, define $\Omega_{r 1}=$ $R^{k \times n}$ and for $j=2, \cdots, k$.

$$
\Omega_{r j}=\left\{\left(u^{0}, \cdots, u^{(n-1)}\right) \in R^{k \times n}:\left|u_{i}^{p}\right| \leqq r_{i p}, i<j, 0 \leqq p \leqq n-1\right\} .
$$

Define $\beta_{j}(r, t)=\sup \left\{\left|g_{j}\left(t, u^{0}, \cdots, u^{(n-1)}\right)\right|:\left(u^{0}, \cdots, u^{(n-1)}\right) \in \Omega_{r j},\left|u_{j}^{0}\right| \leqq r_{j 0}\right\}$, $1 \leqq j \leqq k$.

CoROLlary 2.2. Suppose that g satisfies

$$
\frac{1}{r_{j 0}} \int_{0}^{T} \beta_{j}(r, t) d t \longrightarrow 0 \quad \text { and }
$$

$$
a_{j} \operatorname{sgn}\left(u_{j}^{0}\right) g_{j}\left(t, u^{0}, \cdots, u^{(n-1)}\right) \longrightarrow+\infty \quad \text { as } \quad\left|u_{j}^{0}\right|=r_{j 0} \longrightarrow \infty
$$

uniformly for $\left(t, u^{0}, \cdots, u^{(n-1)}\right)$ in $J \times \Omega_{r j}$ where $a_{j} \in\{-1,1\}$, for $1 \leqq j \leqq k$. Then 2.1 has a T-periodic solution for all $f \in L_{1}\left(J, R^{k}\right)$.

The proof of the corollary will be omitted. Basically the proof consists of showing that Theorem 2.1 applies, first by choosing $r_{1,0}$, then $r_{1, p}, 1 \leqq p \leqq n-1$, and then proceeding to define $r \in R^{k \times n}$, a row at a time.

The second corollary deals with the case that $g$ is superlinear. The proof will be omitted.

Let $R>0$ be fixed and set $B=\left\{x \in R^{k \times n}:|x| \leqq R\right\}$. For $r \in R^{k \times n}$, $0 \leqq r_{i p} \leqq R, 1 \leqq i \leqq k, 0 \leqq p \leqq n-1$, define $B_{r 1}=B$ and for $1<$ $j \leqq k, B_{r j}=\left\{x \in B:\left|x_{i p}\right| \leqq r_{i p}, i<j\right\}$. 
Define $\alpha_{j}(r, t)=\sup \left\{\left|g_{j}\left(t, u^{0}, \cdots, u^{(n-1)}\right)\right|:\left(u^{0}, \cdots, u^{(n-1)}\right) \in B_{r j}\right.$, $\left.\left|u_{j}^{0}\right| \leqq r_{j 0}\right\}, 1 \leqq j \leqq k$.

CoROLlary 2.3. Suppose that for $\left(t, u^{0}, \cdots, u^{(n-1)}\right) \in J \times B$ either

$$
C(L) \longrightarrow 0 \text { as } L \longrightarrow 0 \text {, }
$$

or

$$
C(0)=0 \text { and assume } Q f=0 .
$$

Suppose further that for $1 \leqq j \leqq k, g_{j}$ satisfies

$$
\frac{1}{r_{j 0}} \int_{0}^{T} \alpha_{j}(r, t) d t \longrightarrow 0 \text { as } \quad r_{j 0} \longrightarrow 0
$$

and

$$
a_{j} \operatorname{sgn}\left(u_{j}^{0}\right) Q g_{j}\left(\cdot, u^{0}, 0, \cdots, 0\right)>0
$$

for all small $\left|u_{j}^{0}\right|>0$, for $\left(u^{0}, 0, \cdots, 0\right) \in \partial B_{r j}$ where $a_{j} \in\{-1,1\}$. Then (2.1) has a T-periodic solution for all $f \in L_{1}\left(J, R^{k}\right)$ with $\|f\|_{1}$ sufficiently small.

3. Examples. Here we present some examples to which the results of the previous section apply, hopefully illustrating the conditions which we impose upon the nonlinearity.

EXAMPLE 3.1. Consider the systems

$$
\left\{\begin{array}{l}
x^{\prime \prime} \pm \operatorname{sgn}(x)|x|^{\alpha}+g_{1}\left(t, u, u^{\prime}\right)=f_{1}(t) \\
y^{\prime \prime} \pm \operatorname{sgn}(y)|y|^{\beta}+g_{2}\left(t, x, x^{\prime}\right)+g_{3}\left(t, u, u^{\prime}\right)=f_{2}(t) \\
z^{\prime \prime} \pm \operatorname{sgn}(z)|z|^{\gamma}+g_{4}\left(t, x, x^{\prime}, y, y^{\prime}\right)+g_{5}\left(t, u, u^{\prime}\right)=f_{3}(t)
\end{array}\right.
$$

where $0<\alpha, \beta, \gamma<1, u=(x, y, z), g_{i}$ is continuous for each $i, 1 \leqq$ $i \leqq 5$, and uniformly bounded for $i=1,3,5$. No other conditions are impossed upon $g_{2}$ and $g_{4}$. It follows from Corollary 2.2 that (3.1) has a solution $u$ for all $f_{1} \in L_{1}(0, T)$ and all $T>0$, satisfying $u(0)=$ $u(T), u^{\prime}(0)=u^{\prime}(T)$.

EXAMPLE 3.2. Let $g$ be continuous and uniformly bounded on $[0, T] \times R^{n}$ and let $0 \leqq \alpha<1,0<\beta<1$, then

$$
u^{(n)}+t^{-\alpha} \operatorname{sgn}(u)|u|^{\beta}=g\left(t, u, \cdots, u^{(n-1)}\right)
$$

has a solution $u$ such that $u^{(i)}(0)=u^{(i)}(T), 0 \leqq i \leqq n-1$. This also follows directly from Corollary 2.2.

ExAmPle 3.3. Consider the equation 


$$
\left\{\begin{array}{l}
u^{\prime \prime}+k t^{\alpha} \sin u=f(t), \quad 0<t<1 \\
u(0)=u(1), \quad u^{\prime}(0)=u^{\prime}(1)
\end{array}\right.
$$

where $\alpha>-1$ and $\int_{0}^{1} f(t) d t=0$. Theorem 2.1 implies that (3.3) has a solution, $u$ provided $|k| /(\alpha+1)+\|f\|_{1}<\pi$. Furthermore, $|u(t)|<\pi$ and $\left|u^{\prime}(t)\right| \leqq|k| /(\alpha+1)+\|f\|_{1}$.

EXAMPLE 3.4. Consider the fourth order system

$$
\left\{\begin{array}{l}
x^{i v}+x^{3} g_{1}\left(t, u, u^{\prime}, u^{\prime \prime}, u^{\prime \prime \prime}\right)=f_{1}(t) \\
y^{i v}+y^{3} g_{2}\left(t, u, u^{\prime}, u^{\prime \prime}, u^{\prime \prime \prime}\right)=f_{2}(t), \quad 0<t<T,
\end{array}\right.
$$

where $u=(x, y)$ and $g_{i}$ is continuous and uniformly bounded away from zero, $i=1,2$. Corollary 2.3 implies that (3.4) has a solution $u$ with $u^{(i)}(0)=u^{(i)}(T), 0 \leqq i \leqq 3$, for all $f_{1}, f_{2} \in L_{1}(0, T)$ with sufficiently small norm.

Concluding remarks. The results of this paper are related to some of the results of Mawhin ([7], Theorems 6.1 and 7.1) and Gaines and Mawhin ([4], Theorem IX. 3). Those results rely on one of Mawhin's coincidence degree theorems, as do our results here. The results of [7] and Theorem IX. 3 of [4] both include vector equations of the form considered here, but require the nonlinearity to have sublinear growth. For example, Theorem 6.1 of [7] applied to our equation (1.1) requires that for all $\varepsilon>0$ there exists $\gamma>0$ such that $\left|g\left(t, u^{0}, \cdots, u^{(n-1)}\right)\right| \leqq \varepsilon\left(\left|u^{0}\right|+\cdots+u^{(n-1)}\right) \mid+\gamma$ for all $\left(t, u^{0}, \cdots, u^{(n-1)}\right) \in R^{n+1}$. Moreover, those results all have hypotheses which exclude periodic nonlinearities, such as $\sin (u)$, which our results allow (Example 3.3). In comparing our results with Theorem IX. 3 of [4], one sees that conditions (IX. 14) and (ii) are similar to, but stronger than, conditions (2.5) and (2.6) of our Corollary 2.2. In addition, we allow nonlinearities in the derivative terms and mild singularities in $t$. Theorems 6.1, 7.1 of [7] and IX. 3 of [4] do, however, allow for a more general linear part of the equations considered than do our results here, and Theorem 6.1 of [6] includes functional differential equations.

In our Corollary 2.3 the nonlinear part is superlinear near the origin, and our methods require that the forcing function $f$ be small. If the superlinearity is assumed to hold at infinity, e.g., if $g(x) / x \rightarrow$ $+\infty$ as $|x| \rightarrow \infty$, then our results do not apply. Here the sign of $g(x)$ assumes critical importance (at least in affecting the difficulty of the problem). If the equation considered is, e.g., $(-1)^{n} x^{(2 n)}+$ $g(x)=f$, with $g(x) x \geqq 0$ then a number of results are available in case $n=1$ (concluding vector equations); see, e.g., [1] and many 
results in [5], and many results in [4], and in case $n \geqq 1$ see [8]. For equations such as $(-1)^{n} x^{(2 n)}-g(x)=f$, with $g$ as before, much less seems to be known, but Fucik and Lovicar have shown in [2] that if $n=1$ there is a periodic solution for any periodic $f$. The results of Gaines [3] also apply in some cases of this type.

\section{REFERENCES}

1. J. W. Bebernes and K. Schmitt, Periodic boundary value problems for systems of second order differential equations, J. Differential Equations, 13 (1973), 32-47.

2. S. Fucik and V. Lovicar, Periodic solutions of the equation $x^{\prime \prime}(t)+g(x(t))=p(t)$, Casopis pro pestovani matematiky, roc 100 (1975), 160-175.

3. R. E. Gaines, Existence of periodic solutions to second order nonlinear ordinary differential equations, J. Differential Equations, 16 (1974), 186-199.

4. R. E. Gaines and J. L. Mawhin, Coincidence Degree, and Nonlinear Differential Equations, Lecture Notes in Mathematics, Vol. 568, Springer, Berlin, 1977.

5. H. W. Knowbloch, On the existence of periodic solutions for second order vector differential equations, J. Differential Equations, 9 (1971), 67-85.

6. J. Mawhin, Boundary value problems for nonlinear second order vector differential equations, J. Differential Equations, 16 (1974), 257-269.

7. - Periodic solutions of some vector retarded functional differential equations,

J. Math. Anal. Appl., 45 (1974), 588-603.

8. J. R. Ward, Existence theorems for nonlinear boundary value problems at resonance, preprint 1978, J. Differential Equations, to appear.

Received October 16, 1978 and in revised form March 27, 1979. The first author was partially supported by grant from the faculty research council of Pan American University, and the second author was partially supported by National Science Foundation grant SER 77-04218.

Pan American University

EDINBURG, TX 78539

Current addresses: Texas A \& M University

College Station, TX 77843

and

University of Alabama

University, AL 35486 


\section{PACIFIC JOURNAL OF MATHEMATICS}

\section{EDITORS}

DONALD BABBITT (Managing Editor)

University of California

Los Angeles, CA 90024

HUGO RossI

University of Utah

Salt Lake City, UT 84112

C. C. Moore and ANDrew OGG

University of California

Berkeley, CA 94720
J. DUGUNDJI

Department of Mathematics University of Southern California Los Angeles, CA 90007

R. FINN and J. MILGRAM

Stanford University

Stanford, CA 94305

\section{ASSOCIATE EDITORS}
E. F. BeCKENBACH
B. H. NeumanN
F. WOLF
K. YOSHIDA

\section{SUPPORTING INSTITUTIONS}

UNIVERSITY OF BRITISH COLUMBIA CALIFORNIA INSTITUTE OF TECHNOLOGY UNIVERSITY OF CALIFORNIA MONTANA STATE UNIVERSITY UNIVERSITY OF NEVADA, RENO NEW MEXICO STATE UNIVERSITY OREGON STATE UNIVERSITY UNIVERSITY OF OREGON

\author{
UNIVERSITY OF SOUTHERN CALIFORNIA \\ STANFORD UNIVERSITY \\ UNIVERSITY OF HAWAII \\ UNIVERSITY OF TOKYO \\ UNIVERSITY OF UTAH \\ WASHINGTON STATE UNIVERSITY \\ UNIVERSITY OF · WASHINGTON
}

The Supporting Institutions listed above contribute to the cost of publication of this Journal, but they are not owners or publishers and have no responsibility for its content or policies.

Mathematical papers intended for publication in the Pacific Journal of Mathematics should be in typed form or offset-reproduced, (not dittoed), double spaced with large margins. Please do not use built up fractions in the text of the manuscript. However, you may use them in the displayed equations. Underline Greek letters in red, German in green, and script in blue. The first paragraph or two must be capable of being used separately as a synopsis of the entire paper. Please propose a heading for the odd numbered pages of less than 35 characters. Manuscripts, in triplicate, may be sent to any one of the editors. Please classify according to the scheme of Math. Reviews, Index to Vol. 39. Supply name and address of author to whom proofs should be sent. All other communications should be addressed to the managing editor, or Elaine Barth, University of California, Los Angeles, California, 90024.

50 reprints to each author are provided free for each article, only if page charges have been substantially paid. Additional copies may be obtained at cost in multiples of 50 .

The Pacific Journal of Mathematics is issued monthly as of January 1966. Regular subscription rate: $\$ 84.00$ a year (6 Vols., 12 issues). Special rate: $\$ 42.00$ a year to individual members of supporting institutions.

Subscriptions, orders for numbers issued in the last three calendar years, and changes of address should be sent to Pacific Journal of Mathematics, P.O. Box 969, Carmel Valley, CA 93924, U.S.A. Older back numbers obtainable from Kraus Periodicals Co., Route 100, Millwood, NY 10546.

PUBLISHED BY PACIFIC JOURNAL OF MATHEMATICS, A NON-PROFIT CORPORATION

Printed at Kokusai Bunken Insatsusha (International Academic Printing Co., Ltd.). 8-8, 3-chome, Takadanobaba, Shinjuku-ku, Tokyo 160, Japan.

Copyright (C) 1979 by Pacific Journal of Mathematics Manufactured and first issued in Japan 


\section{Pacific Journal of Mathematics}

\section{Vol. 84, No. $2 \quad$ June, 1979}

Somesh Chandra Bagchi and Alladi Sitaram, Spherical mean periodic

functions on semisimple Lie groups ........................ 241

Billy Joe Ball, Quasicompactifications and shape theory............. 251

Maureen A. Bardwell, The o-primitive components of a regular ordered permutation group ................................ 261

Peter W. Bates and James R. Ward, Periodic solutions of higher order

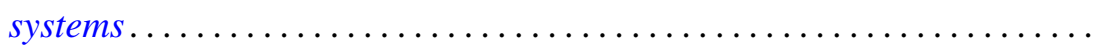

Jeroen Bruijning, A characterization of dimension of topological spaces by totally bounded pseudometrics......................... 283

Thomas Farmer, On the reduction of certain degenerate principal series

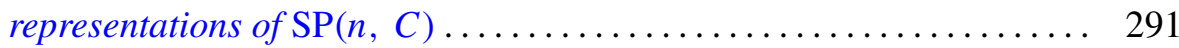

Richard P. Jerrard and Mark D. Meyerson, Homotopy with m-functions . . . . 305

James Edgar Keesling and Sibe Mardesic, A shape fibration with fibers of

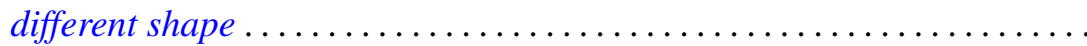

Guy Loupias, Cohomology over Banach crossed products. Application to bounded derivations and crossed homomorphisms ...............

Rainer Löwen, Symmetric planes ........................ 367

Alan L. T. Paterson, Amenable groups for which every topological left

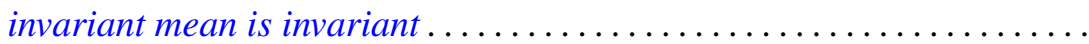

Jack Ray Porter and R. Grant Woods, Ultra-Hausdorff H-closed extensions

Calvin R. Putnam, Operators satisfying a $G_{1}$ condition .

Melvin Gordon Rothenberg and Jonathan David Sondow, Nonlinear smooth representations of compact Lie groups..............

Werner Rupp, Riesz-presentation of additive and $\sigma$-additive set-valued measures.

A. M. Russell, A commutative Banach algebra of functions of generalized variation

Judith D. Sally, Superregular sequences

Patrick Shanahan, On the signature of Grassmannians . . 